\title{
The Effects of Intergenerational Transmission on Education
}

\author{
Chun Wang, ${ }^{1, *}$ \\ 1. Shanghai Private New Century Primary School, No. 2, Lane 374, Xingguo Road, Changning District, Shanghai 200052, China \\ *: All corresponding should be sent to: Chun Wang. \\ Author's Contact: Chun Wang, E-mail: 13916057293@qq.com \\ DOl: https://doi.org/10.15354/si.21.re260 \\ The author declares no competing interest.
}

\begin{abstract}
Intergenerational transmission exists in parents' and children's educational attainment as well as in biological genetic inheritance. In fact, it impacts educational attainment transfer across generations in many ways. This article elaborates from different angles on the characteristics, disparities and causes of intergenerational education transmission, and explores the effects of intergenerational transmission inequality on education and the implications of this study.
\end{abstract}

Keywords: Intergenerational Transmission; Education; Inequality in Resources

Science Insights, 2021 December 28; Vol. 39, No. 5, pp.401-406.

(C) 2021 Insights Publisher. All rights reserved.

(c) (i) (s) Creative Commons Non Commercial CC BY-NC: This article is distributed under the terms of the Creative Commons Attribution-NonCommercial 4.0 License which permits non-commercial use, reproduction and distribution of the work without further permission provided the original work is attributed by the Insights Publisher.

$\mathrm{W}$ ITH the rapid growth of global economy, the inequality in individuals' earnings is gradually intensified. A certain correlation is shown between parents' and children's social income, which means the economic resource distribution, is not functioning equally in providing opportunities for families from different social strata. This disparity exhibits prominent intergenerational transferability and persistency. Intergenerational transmission exists objectively because of social development and economic mobility.

In social life, parents tend to hold strong expectations of children's social achievement irrespective of the above objective existence. A considerable number of parents expect unreasonably their children to achieve ideal social status and an elevated economic status, while ignoring the significant influence of intergenerational transmission, which causes pressure to children.

To explore the impact of intergenerational transmission, researchers must consider education as a substantive factor, as it is one of the most important social activities for individuals in modern civilization, and social resource inequality caused by intergenerational transmission leads directly to educational resource inequality. Research on disparities in intergenerational education transmission and the causes is one of the key pathways to understanding the inequality in educational resources.

\section{Summary}

Intergenerational transmission refers to the phenomenon that parental capabilities, characteristics, behaviors, concepts, and social achievement are transferable to their children. The effects of intergenerational transmission are positively correlated to the similarities between parents and children in various aspects. So far, many attributes and phenomena are identified to be intergenerationally transmissible, including educational attainment, social status, cultural values, and even aggressive conducts. Among them, intergenerational transmission of educational attainment is an important topic in this research field (1). Intergenerational education transmission refers to the extent of change in the children's educational attainment level with parental educational attainment level as references. Generally speaking, under the influence of a higher parental education level, the children's educational level is relatively higher, and the opposite is also true, which demonstrates a positive correlation between parents' and children's educational achievement.

Studies from various countries indicate that the education acquired by parents have significant effects on the educational level of their children. Restuccia \& Urrutia (2), for example, developed a quantitative model of intergenerational transmission of human capital and income disparity, and found that, in America, approximately $50 \%$ of the intergenerational persistence of earnings was accounted for by parental investment in education, 
which demonstrated the important role education plays in human capital transmission. Differences in educational level cause inequality not only in the same generation but also in the following generation through intergenerational transmission (3).

DeBaryshe et al. (4) reported after research that there was a positive correlation between American parents' educational achievement and their children's academic achievement $(r=$ 0.15 , and the explanation rate of parents to their children is $26 \%$ ) and that there was also a positive correlation $(r=0.4)$ for their English counterparts. Similar conclusions were drawn from the surveys on Indonesian women.

Raftery \& Hout (5) put forward maximally maintained inequality hypothesis (MMI), according to which, economically advantaged families and those with advantaged parental educational background always pursued maximized educational opportunities for their children. Only when the demand for a specific level of education approaches or reaches $100 \%$ for the upper class, the inequality of educational opportunities would weaken. Otherwise, the educational opportunities would remain in the form of maximally maintained inequality. This theory emphasizes that there is an inverted U-shaped relationship between educational inequality and the amount of human capital into education (6)

\section{Disparity in Intergenerational Education Transmission}

Researchers across the world prove that intergenerational transmission affects children's educational achievement. There is growing concern over the equity of educational attainment transfer across generations. What disparities cause the inequality in intergenerational education transmission? The following analysis is made to answer this question.

\section{Racial and Regional Disparity}

Using mature theories and methodologies, scholars have been implementing assessment on intergenerational education transmission and found substantial differences in intergenerational education transmission across race and region.

\section{Racial Disparity}

Nimubona \& Vencatachellum (7) conducted an empirical analysis on racial disparities in intergenerational education transmission in South Africa by using survey data. The result of the study revealed that intergenerational education mobility of blacks was much lower than that of whites, and that among blacks, males had a lower intergenerational education mobility than females, and the poorest had the lowest intergenerational education mobility. It was believed that the causes for this result were higher accessible thresholds for blacks than for whites in terms of credit market, availability and quality of schools.

\section{Regional Disparity}

Overall, intergenerational education mobility in developed countries is higher than in developing countries. Specifically, South American countries are the strongest in intergenerational education mobility, followed by the USA and Europe, with North European countries being the weakest (8).

In the context of regional disparities in Mainland China and its special household registration system, $\mathrm{Wu}$ (9), under the guidance of maximally maintained inequality hypothesis (MMI) and effectively maintained inequality hypothesis (EMI), performed an analysis on the educational achievements of China's urban and rural residents since its reform and opening to the outside world, by referring to data from China's General Social Survey (CGSS) 2008. The results of the analysis indicate that the educational level in urban areas on average is higher than that in rural areas, and that parental registered residence has significant effects on the child educational attainment. When the parents' residence is registered in city, the possibility for their children to access key schools, non-vocational education and proper academic tracks was much higher. This access, in turn, could assure the children higher education quality. Under the circumstances of huge disparities in educational resources among all the provinces and the household registration system typical of China, individuals' educational level is heavily impacted by their registered household residences. Consequently, the average years of schooling among rural children are shorter than their urban counterparts. In addition, rural areas bear higher intergenerational education transmission elasticity and lower mobility than urban areas, which makes upward mobility very difficult. To some extent, intergenerational education transmission assures part of the population educational rights at the expense of the rest.

\section{Stage Disparity}

Research indicates that intergenerational education transmission varies in different schooling stages. The school progression model was created by Mare (10) to examine the distribution of educational opportunities in each schooling stage. The model was used in a study by a Chinese scholar to determine how intergenerational education transmission differed in different stages in the context of China (8). The study was based on the data in 1991, 2000 and 2011 from China and divided the whole education period into four stages, namely the primary school stage, the transition stage from primary to secondary school, the transition stage from junior to senior secondary school and the transition stage from secondary school to college. After the analysis on the regression results of the school progression model, conclusions were reached as follows: Parental education level exerted the greatest influence on the child enrollment success rate (enrollment probability/1-enrollment probability) in the primary school stage, which rose by $30 \%$ with one year increase of parental education; Parental education influence declined on the fourth stage, with $18 \%$ rise in child enrollment success rate against one year increase of parental education.

\section{Sources of Disparity in Intergenerational Ed- ucation Transmission}

After the confirmation of the existence of intergenerational education transmission by experts and scholars from various countries, raises the question of how disparities in intergenerational education transmission take place, which becomes one of the major topics in the study on intergenerational education transmission. Answering this question requires research on the working mechanisms of intergenerational education transmission. 


\section{Family Culture Reproduction}

The theory of culture reproduction initiated by Bourdon (11) explains how family background factor is converted into children's educational advantages. The model of culture reproduction asserts that compared with parents with low education level, those with higher education level enable their children to obtain more educational opportunities, that is, the children are able to inherit and to carry on parents' educational advantages so as to realize the reproduction of household cultural status. From this angle, there are three major factors facilitating the intergenerational education transmission.

\section{Household Economic Capital}

Household economic capital refers mainly to family income, the financial sources of educational expenditure in the family. Jiang and Yan (12) measured household economic capital by family total earnings and family assets and found that family income had long term effects on children's academic performance and that family asset value was related to their academic achievements. Recently, with rapid economic and social development, occurrence of market shock and acceleration of social stratification, household economic capital is imposing increasing influence on intergenerational education transmission, and its working mechanism begins to change. Children born into families of management level with more economic capital are significantly advantaged in school progression ratio (13).

Higher educational achievement means a rise in the educational cost, which has little impact on the children from economically advantaged families in their school progression. While, for those underclass families with low parental educational level, the ever-increasing educational expenditure contradicts their family income, leading to a decrease in the children's school progression ratio.

\section{Family Cultural Capital}

The concept of cultural capital was put forward by Bourdon (11), a sociologist, referring to cultural objects delivered through educational practice. Cultural capital exists in individuals' personality disposition, cultural objects (books) and cultural systems (exams). Cultural capital plays an important role in children's academic success as it can cultivate their learning motivations and desire for better academic performance.

Researchers examine the influences of cultural capital on children's academic performance and education attainment in terms of home cultural atmosphere creation, parental education expectations and communications on schoolwork. Their research results manifest that those families which equip their children with more school supplies, organize more learning activities (for example, reading, museum visiting) (14) and have more parent-child and parent-school communications (15) tend to produce children with better academic achievements.

Economically advantaged families with higher parental educational level are capable and willing to provide their children with superior cultural capital, which, in turn, drives them to improve their academic performance. In contrast, those economically disadvantaged families with lower parental educational level are normally unable to supply their children with good quality home cultural capital and their probability of achieving high-grade academic performance is much lower. Therefore, there is a positive correlation between home cultural capital and intergenerational education transmission.

\section{Family Social Capital}

Social capital is resources embedded in social network. Though not possessed directly by individuals, those occupy key or higher-level positions in the network can attain the resources through direct or indirect social relationships (16). Families differing in social class hold different positions in the network, resulting in possession of differentiated amount of social capital. Families of higher social status own more social capital and are thus able to provide their children with good quality educational resources and more school progression opportunities.

With the rapid growth of economy and intensifying social stratification, the social capital gap among different strata is widening, leading to the reality that, compared with lower class families, higher class ones can utilize more social capital, which means more educational resources. As a result, those children from high class families yet with low school performance can still obtain adequate educational opportunities.

Relevant research results confirm the function of social capital as media of intergenerational education transmission and report that children from high classes, including government and social administrators, management, private business owners, represent higher education enrollment rates 2 to 6 times higher than the average for the whole society, which means far more educational opportunities than social average. In contrast, children from lower classes with less social capital, such as clerks, industrial laborers, agricultural workers, and the unemployed, represent lower enrollment rates of higher education than the average. The biggest gap between the highest and the lowest class is shockingly 14 times (17). Manipulation of family social capital is proved to have far-reaching impacts on children's lifelong educational attainment, career orientations and workplace outcomes.

\section{Education Investment}

Intergenerational education investment is one of the determinants of school success. Education investment covers not only family capital investment in education, but also time investment and intergenerational education investment willingness.

\section{Family Investment Capacity}

Intergenerational education investment capacity is positively correlated to parental educational level. Parents with higher education level can rear their children in more sensible ways, provide more powerful financial support, and offer them better living environment, learning environment and better nutrition. Greater education investment capacity suggests higher probability of child school success and sequential stronger correlation of Intergenerational education transmission

Plug \& Vijverberg (18) noted in his study on intergenerational education transmission that, apart from parental education level, there might be other factors impacting research results, for example, genetic inheritance. To avoid data bias caused by variable interference, Plug \& Vijverberg collected data on educational attainment of adopted and biological children living in the 
same families and data on their family income. The analysis results verify that there is a causal relationship between parental earnings and child education level. Household income has the same effect on adopted and own birth children.

\section{Family Time Investment and Efficiency}

Guryan (19) studied intergenerational education transmission from the perspective of efficiency. His analysis results based on samples from 14 countries suggest that families of different social strata differ in their human capital investment in offspring's education and also differ in time investment efficiency. In high class and high educational level families, parents spend more time companying children, and the latter are fonder of the former's company. The effectiveness of parental companionship of these families is relatively higher.

In Guryan's study, Intergenerational time investment encompasses time for daily care (breastfeeding, putting children to sleep, feeding, and changing diapers, etc.), time on education (reading storybooks to children, moral educating, homework tutoring, attending parents' meetings and school activities, etc.) and time on entertainment (playing games with children, outdoor activities, participating school sports, visiting zoo, etc.)

This study suggests family time investment is of great significance to children's education level. It also shows that parents with college education spend 4.5 hours more per week taking care of their children than those with secondary school or even lower education. One of the possible reasons is that parents with higher level of education represent higher efficiency in time investment and children enjoy longer company from better educated parents. It can be concluded that the difference in family time investment efficiency is one of the factors influencing in tergenerational education transmission.

\section{Family Education Investment Willingness}

Castello-Climent \& Domenech (20), the builders of overlapping generation model, argued from the perspective of life expectancy that in families with higher parental educational level, children have higher life expectancy, which encourages stronger parental investment willingness and increases children's willingness to be educated. Kirchsteiger \& Sebald's (21) research on intergenerational education transmission suggested that families with higher level of parental education attach great importance not only to investing into education, but also to transmitting educational wisdom to their offspring to build a family tradition which values education investment and secures intergenerational education transmission. Thus, parental education level is related to child education level through influencing education investment willingness and ideas (22).

\section{Personal Education Expectations}

Some scholars adopt a psychological approach, use personal educational expectations as intermediate mechanism in intergenerational education transmission, and end up discovering that educational expectations can be converted into an advantage in obtaining a higher level of educational achievement.

Wang \& Shi (23), using personal educational expectations as intermediate mechanism in intergenerational education transmission and employing data from survey on current family life of Shanghai residents 2010, studied how the college education expectation in children's adolescence influenced their final educational levels. It was found that in families with higher parental educational level, children hold higher expectations of college education, which can be turned into incentives for further education and become an advantage in striving for higher level of education (8).

\section{Implications of Studies on Intergenerational Education Transmission Face the Inequality Caused by Intergenera- tional Education Transmission}

Education, as a mediator in intergenerational transmission, performs the function of social differentiation and stratification, driving people to pursue higher social status and highly recognized professions. However, to some extent, intergenerational education transmission hinders lower-middle class families from moving up the social ladder. In the context of intensifying school enrollment competition and soaring education costs, it is getting more difficult to interrupt the intergenerational transmission of poverty by means of education, for intergenerational education transmission is weakening social mobility (24).

Gaps in educational level and income among children depend largely on those of the parents. There is a positive correlation between child socio-economic achievement and parent social network capital and social status. Therefore, parents must face the practical problems triggered by intergenerational education rationally when expecting the younger generation to transcend their social status in climbing the social ladder.

\section{Recognize the Existence of Inequality Related to Intergenerational Education Transmission}

Intergenerational transmission itself is a neutral concept. A family's possession of social wealth and social resource is normally the outcome of accumulation for generations. It is a natural phenomenon that superior individuals acquire social resources they deserve (25).

Attempts to re-allocate social resources by means of interrupting intergenerational education transmission to achieve absolute equal distribution of social resources will produce the circumstance that intergenerational resource transmission becomes impossible and thus high-quality individuals will lose motivation for further achievement. In addition, intergenerational education transmission makes it possible for core educational resources to be effectively employed by high-quality individuals.

\section{Alleviate Inequality in Intergenerational Edu- cation Transmission through Rational Em- ployment of Education}

To avoid negative effects of slowing social mobility, one should consider disparities in intergenerational education transmission. Parents should think over those influential factors related to themselves and their impacts on children and find suitable social resources to facilitate their children's school progression, rather than seek for core educational resources blindly at the expense of current life.

To reduce inequality in intergenerational education trans- 
mission, factors affecting this transmission must be identified and appropriate adjustments be made to those disparities discussed:

(i) Parental own factors. Consider parental educational level, social class, social capital, and make reasonable judgment on child educational attainment.

(ii) Home culture factor. Upgrade home cultural environment and make proper investment to improve children's cultural literacy.

(iii) Time investment. Parents should dedicate more time and energy to meet children's psychological needs and get involved in their growth, instead of concentrating only on their educational outcomes.

When projecting educational expectations for their children, parents should consider various factors including their own educational level, home cultural production, and household educational investment. Attempts to reduce disparities within family capability are recommended. Any parental expectation that children should make great leaps upward on the social ladder, regardless of family background, is neither realistic nor wise.

\section{References}

1. Chi LP, Yu GL. Mechanisms of intergenerational transmission of educational attainment: from the perspective of capital and communication. Educ Res $2011 ; 2011(9): 22-28$.

2. Restuccia D, Urrutia C. Intergenerational persistence of earnings: The role of early and college education. Am Econ Rev 2004; 94(5):1354-1378. DOI: https://doi.org/10.1257/0002828043052213

3. Hendel I, Shapiro J, Willen P. Educational Opportunity and Income Inequality. J Public Econ 2005; 89 (5-6):841-870. DOI: http://dx.doi.org/10.1016/i.jpubeco.2004.11.004

4. DeBaryshe BD, Patterson GR, Capaldi DM. A performance model for academic achievement in early adolescent boys. Develop Psychol 1993; 29(5):795-804. DOI: https://doi.org/10.1037/0012-1649.29.5.795

5. Raftery $A E$, Hout M. Maximally maintained inequality: Educational stratification in Ireland. Sociol Educ 1993; 65:41-62. DOI: https://doi.org/10.2307/2112784

6. Tang DS, Han XF. Regional educational human resources and intergenerational education transmission: Suppression or promotion. Modern Educ Admin 2020; 2020(4):25-31. DOI: https://doi.org/10.16697/j.1674-5485.2020.04.004

7. Nimubona AD, Vencatachellum D. Intergenerational education mobility of black and white South Africans Popul Econ 2007; 20(1):149-182. DOI: https://doi.org/10.1007/s00148-006-0120-9

8. Li XM. A dynamic study on intergenerational education transmission in China. Doctoral dissertation. Shanxi University of Finance and Economics. 2018.

9. Wu YX. Inequality in educational opportunities between urban and rural residents in China and its evolution (1978-2008). Chin Soc Sci 2013; 2013(3):4-21 .

10. Mare RD. Statistical models of educational stratification: Hauser and Andrew's model for school transitions. Sociol Methodol 2006; 36:27-37. DOI: https://doi.org/10.1111/j.1467-9531.2006.00173.x

11. Bourdon R. Education, Opportunity, and Social Ine-

quality: Changing Prospects in Western Society. London: John Wiley. 1974.

12. Jiang GH, Yan GF. Household capital and disparity between urban and rural academic achievements: An empirical analysis. Youth Study 2006; 2006(6):28-34. DOI: https://doi.org/10.3969/j.issn.1008-1437.2006.06.004

13. Li Y. Social change and generation mechanism of educational inequality. History Teach 2006; 2006(3S):1.

14. Sullivan A. Cultural capital and educational attainment. Sociology 2001; 35(4):893-912. DOI: https://doi.org/10.1177/0038038501035004006

15. Gonzalez A, Wolters CA. The relation between perceived parenting practices and achievement motivation in mathematics. J Res Childhood Educ 2006; 21(2):203-217. DOI: https://doi.org/10.1080/02568540609594589

16. Xin ZQ, Chi LP. Teenagers in Social Change. Beijing: Beijing Normal University Press. 2008.

17. Xie ZX. Wang WY. Differences of higher education enrollment opportunities for children from all social strata in China from the perspective of higher education popularization. J Educ 2008; 2008(2):65-74. DOI: https://doi.org/10.3969/j.issn.1673-1298.2006.02.008

18. Plug E, Vijverberg W. Does family income matter for schooling outcomes? Using adoptees as a natural experiment. Econ J 2005; 115(11):879-906. DOI: https://doi.org/10.1111/j.1468-0297.2005.01023.x

19. Guryan J, Hurst E, Kearney MS. Parental education and parental time with children. J Econ Persp 2008; 22(3):23-46. DOI: https://doi.org/10.1257/jep.22.3.23

20. Castello-Climent A, Domenech R. Human capital inequality, life expectancy and economic growth. Econ J 2008; 118(4): 653-677. DOI: https://doi.org/10.1111/i.1468-0297.2008.02136.x

21. Kirchsteiger $G$, Sebald A. Investments into education: Doing as the parents did. Eur Econ Rev 2009; 54(4):727-739. DOI: https://doi.org/10.1016/i.euroecorev.2009.09.004

22. Zhang S, Zeng QB. A review of the effect of the in- 
tergenerational human capital transmission in education. Econ Persp 2011; 2011(8):129-134.

23. Wang FQ, Shi YW. Family background, educational expectation and college degree attainment: An empirical study based on Shanghai survey. Chin J Sociol 2014; 34(1):21. Available at:

https://www.society.shu.edu.cn/CN/Y2014/V34/11/17

24. Xu SJ, Zhou DY. The intermediary role of education in intergenerational social class transmission. J Soc sci 2017; 2017(9):91-100. DOI:

https://doi.org/10.13644/j.cnki.cn31-1112.2017.09.00 $\underline{8}$

25. Cui HJ. On the characteristics of the middle class in modern England. J Liaocheng Univ (Soc Sci Ed) 2021; 2021(4):73-78. DOI:

https://doi.org/10.16284/i.cnki.cn37-1401/c.2021.04.0 11 